\title{
A Relationship Model between Top Management Team Cognitive Heterogeneity and Strategic Decision Quality and Its Implications for Sustainability
}

\author{
Qiannan Wang $\mathbb{D}^{1},{ }^{1}$ Yuhui Ge $\mathbb{D}^{1},{ }^{1}$ and Cuihua $\mathrm{Hu} \mathbb{D}^{2}$ \\ ${ }^{1}$ Business School, University of Shanghai for Science and Technology, Shanghai, China \\ ${ }^{2}$ School of Information Management, Shanghai Lixin University of Accounting and Finance, Shanghai, China \\ Correspondence should be addressed to Cuihua Hu; hucuihua@lixin.edu.cn
}

Received 10 August 2020; Revised 26 September 2020; Accepted 1 October 2020; Published 13 October 2020

Academic Editor: Wei Zhang

Copyright (c) 2020 Qiannan Wang et al. This is an open access article distributed under the Creative Commons Attribution License, which permits unrestricted use, distribution, and reproduction in any medium, provided the original work is properly cited.

\begin{abstract}
To achieve sustainable development, a top management team (TMT) and the quality of its strategic decisions on sustainability are critical. This paper builds a relationship model between top management team (TMT) cognitive heterogeneity and the quality of strategic decisions. This research is important because TMT cognitive heterogeneity can comport decision-making schemes with complex and changing environments. Specifically, this paper explores the intermediary role of the team fusion process composed of different shareholders' agents in integrating TMT heterogeneous cognition to improve the quality of strategic decisions. It adopts the upper echelon theory, which proposes that decision-makers have limited rationality and face difficulty in collecting and analyzing information in complex and changing environments. A questionnaire survey of 107 Chinese enterprises was conducted. Through the research framework of "cognitive heterogeneity-team fusion-strategic decision quality," this paper constructs a moderated mediator model with entrepreneurial spirit as the moderating variable. Based on statistical analysis, the following results and contributions are obtained. First, TMT cognitive heterogeneity positively affected strategic decision quality. Second, two dimensions of team fusion-information integration and emotional fusion-mediated the relationship between TMT cognitive heterogeneity and strategic decision quality. Third, entrepreneurial spirit positively moderated the relationship between information integration and strategic decision quality, as well as the relationship between emotional fusion and strategic decision quality. The implications of our results related to sustainability are also discussed.
\end{abstract}

\section{Introduction}

Sustainability has become a critical issue worldwide. To this end, top management team (TMT) of a firm and the quality of their strategic decisions on sustainability play important roles. This is especially true in developing countries. In China, the reform of state-owned enterprises (SOEs) has been highly complex and challenging. It emphasizes not only optimizing ownership and governance structures but also improving management [1]. Given the complexities and uncertainties of reform, whether the mix of state-owned and private capital will promote high-quality sustainable development ultimately rests with the top management team (TMT), which oversees strategic decision-making. The low- carbon sustainable development has become a potential mechanism for enterprises to gain competitive advantages and an important aspect of enterprise strategic management. TMT members representing different shareholders have different values, cognition, and behavioral habits, including those related to low-carbon and sustainable development. Managers from SOEs tend to be administratively focused, while those from private enterprises tend to be paternalistic. It is found that managers' perceptions of different types of shareholder drive the sustainability practices in firms [2]. Managers' different cognition of low-carbon and sustainable development leads to different strategies on sustainability. The reform process is bound to undergo adaptation, where a lack of TMT fusion will only increase friction and hinder the 
reform. The fusion of TMT members will help maintain the sustainable development of mixed-ownership enterprises. Building TMTs through entrepreneurship is key to enhance innovation and sustain reform. Studies on mixed-ownership reform have mainly focused on ownership and governance structures, including how to mix the property rights or capital of enterprises [3-5]. However, there is a lack of research on how TMT members, representing different shareholders, can mutually integrate.

\section{Literature Review}

Green management of enterprises often requires the change of the existing corporate culture, which requires the support of TMT [6]. Managers with strong environmental awareness can identify the market opportunities of green innovation [7]. According to upper echelons theory proposed by Hambrick and Mason [8], the TMT is the main strategic decision-maker regarding enterprise strategy. Cognitive heterogeneity and behavior processes largely determine the quality of strategic decisions and the effects of corporate governance. According to information and decision theory, heterogeneity of team members positively affects team performance [9], while social classification theory does the opposite [10]. Olson et al. [11] found that Chinese TMT heterogeneity has a negative effect on decision-making performance due to collectivism and the avoidance of uncertainty. TMT members with different cognitions have different beliefs regarding strategic objectives, and the results of collecting and processing information are diverse [12]. The TMT is the actual executor of the mixed-ownership reform. Team members strengthen the complementary advantages and resources of state-owned and private capital, and they promote the mixed-ownership reform of SOEs through team processes, such as transmitting information as well as easing ideological barriers [13]. There is a need, therefore, to investigate how the cognitive heterogeneity of TMTs, after mixed-ownership reform, can promote cooperation and improve the quality of strategic decisions through psychological and behavioral integration.

Mixed-ownership reform encourages market mechanisms to improve SOE management; thus, an entrepreneurial spirit is preponderant for effectuating high-quality change and development [14]. According to Drucker [15], the entrepreneurial spirit is unrelated to ownership, and anyone with the courage to make decisions, implement reforms, pursue innovation, and create value can display it. Entrepreneurial spirit reflects the strategic orientation of decisionmakers. At the individual level, innovation is the essential characteristic of entrepreneurship, whereas, at the team level, it has richer connotations. A TMT with an entrepreneurial spirit can help its heterogeneous members judge potential risks and, by jointly shouldering them, can alleviate the concomitant pressures and possible economic losses; thus, it is collaborative and progressive [16]. Currently, research on the entrepreneurial spirit at the team level is lacking.

Based on the research framework of "cognitive heterogeneity-team fusion-strategic decision quality," this paper constructed a moderated mediator model with entrepreneurial spirit as the moderating variable. The effects of TMT cognitive heterogeneity on strategic decision quality in mixed enterprises was empirically tested, along with the team fusion's mediating function under the moderation of entrepreneurship. This work has theoretical and practical value for studying the influencing factors of strategic decision quality in mixed enterprises in China and for improving TMTs' governance efficiency.

\section{Theory and Hypotheses}

3.1. Cognitive Heterogeneity and Strategic Decision Quality. Enterprises should consider environmental responsibility when formulating business strategy. The concept of sustainable development and green business model will redefine the traditional business models. Enterprises can actively consider the interactions between business and natural environment to form new competitive advantages. Green strategy is a new strategy for gaining competitive advantages, which involves not only financial benefits but also environmental benefits and corporate responsibility for nature and society. It is more complex than strategic decision in general. The TMT directly affects enterprise competitiveness and future sustainability, since it is at the heart of enterprise decision-making and development. In a complex business environment, TMTs' choices and implementation of enterprise strategy are influenced by their cognitive ability, values, and so on [17].

Strategic decision quality usually refers to the contribution of decision-making to achieving organizational goals [18]. When evaluating strategic decision quality, it is important to consider the contribution of strategic decisions to realizing organizational innovation objectives and improving the allocation of resources. Decision-makers' cognition includes their capacity to analyze and manage problems, as well as their strategic wisdom, which determine whether they can make strategic decisions and create competitive advantage [19]. According to upper echelons theory, decision-makers have limited rationality and face difficulty in collecting and analyzing information in complex and changing environments [20]. High-quality decisions should multidimensionally consider both internal and external information. Thus, enterprises need collaborative TMTs and those have diverse cognition so they will not be limited by prior experience or neglect important factors in decisionmaking [21].

TMT cognitive heterogeneity refers to differences in the cognition of important concepts among team members [22]. Due to the diversified ownership structure of mixed-ownership enterprises, TMT members represent the interests of different shareholders with different perceptions of corporate innovation and decision-making. Strategic decisionmaking involves the processing of information. Cognitive heterogeneity provides different perspectives for the TMT to discover opportunities and identify risks [23], increasing the possibility of making high-quality strategic decisions. The different backgrounds and expertise of TMT members in mixed enterprises can help them cope with business challenges related to environmental uncertainty and rapid 
technological change, and such diverse cognitive resources can also positively influence enterprise innovation [24].

Diversified cognition can amplify the signals of key cognitive resources on the team and help members identify useful information, thus enhancing the team's core creativity [25]. According to Sahaym et al. [26], TMT heterogeneity can promote the use of venture capital (within certain limits), and the risk-taking propensity of team members is the driving factor of the company's risk-taking behavior. The reorganization and integration of different types of capital driven by innovation cause enterprises to face more risks and challenges. TMTs should have not only diversified cognition of fuzzy and complex information but also an innovative spirit for undertaking risks so they can make high-quality strategic decisions that will meet the requirements of mixed-ownership reform.

TMT cognitive heterogeneity can comport decisionmaking schemes with complex and changing environments. TMTs face complex innovation-driven environmental pressures from uncertainty; thus, high cognitive heterogeneity is especially needed for strategic decision-making. TMT's heterogeneous knowledge is important for overall managerial and innovation performances [27]. Therefore, when TMT members have heterogeneous cognitive and information-processing abilities, they will be more sensitive to both threats and innovation opportunities, which can increase the possibility of making timely decisions related to innovation and development. Meanwhile, a lack of heterogeneity will reduce the team's cognitive flexibility, hindering their willingness to obtain more information or make changes. Therefore, with mixed shareholders, TMT cognitive heterogeneity enables companies to make innovative, high-quality decisions that can create breakthroughs in business management and production technology. Thus, we propose the following hypothesis.

Hypothesis 1. TMT cognitive heterogeneity positively affects strategic decision quality in mixed enterprises.

3.2. Mediating Effect of Team Fusion. The sustainable strategy of enterprises requires the active participation of TMT to balance their interests. It also requires changing the traditional organizational culture. Enterprises should establish an environment-oriented thinking, consider the ecological environment in their work, establish a sense of responsibility for environmental protection, cultivate a sustainable oriented organizational culture, and establish an organizational environmental reputation. The SOEs typically bear more social responsibilities. Their contributions to environmental protection are an important measure of their managers' performance. Therefore, managers from SOES are more aware of environmental protection and sustainability, while those of non-SOEs pay more attention to economic interests than to environmental protection.

Mixed capital is the external expression of the mixedownership reform of SOEs. To realize the complementary advantages of different ownerships and to avoid "mixture without fusion," it is important to integrate production factors for optimal resource allocation [28]. According to
Chen and $\mathrm{Lu}$ [13], mixed-ownership reform intends to overcome systemic barriers between SOEs and private enterprises and bridge their TMTs. Such fusion of TMT members is key to integrating shareholder resources, improving the efficiency of corporate governance, and achieving sustainable development.

Fusion is a process of team interaction, which can help the team become coherent through information exchange and emotional communication, thereby integrating resources and pursuing joint decision-making. The team effectiveness model (IPO model) incorporates a characteristic variable and a process variable into a unified research framework. The literature has found that the process variable not only plays an important role in team effectiveness but also functions as a mediator between the characteristic variable and the result variable [29]. Cognitive heterogeneity in TMTs is manifested through internal interactions [30], and team performance is improved via high-level interpersonal interactions within the teams [31]. Ge [32] proposed that decision-making interactions in TMTs include two processes: information and emotional. Therefore, our study examines the mediating effect between TMT cognitive heterogeneity and strategic decision quality in terms of information integration at the behavioral level and emotional integration at the psychological level.

The information integration of TMTs involves transmitting, communicating, and discussing information collected and processed by members. Through these activities, the integration of information can be realized, which is an important process for team members to integrate. TMT decision-making is the process of collecting and processing that information. In upper echelons theory, TMTs must promote cooperation and joint decision-making through high-quality information exchange to effectively formulate and implement organizational strategic plans [33]; decisionmaking levels can only be improved by fully sharing information and resources. High-level information exchange among TMTs in mixed enterprises can facilitate the full sharing of information needed for strategic decision-making. In addition, information sharing can reduce the pressures caused by disagreements among members.

From the perspective of interactive cognition, when members possessing different knowledge, skills, thinking styles, and perspectives communicate information and viewpoints, they also contribute to creative decision-making and to finding better solutions [34]. TMT cognitive heterogeneity can thus help overcome cognitive bias in group decision-making and identify optimal choices by increasing discussion through the dissemination of knowledge and information [35]. In mixed enterprises, TMT members collect and process information from the different perspectives of the shareholders, which can provide more diverse and comprehensive data for decision-making. This helps to facilitate joint decision-making, thus avoiding the "groupthink." Therefore, in decision-making interactions among members of mixed enterprises, cognitive heterogeneity affects the validity of information integration, which in turn affects strategic decision quality.

Thus, we propose the following hypothesis. 
Hypothesis 2. Information integration mediates the process of TMT cognitive heterogeneity, influencing strategic decision quality in mixed enterprises.

Fusion means cohesion, which refers to the closeness of the connections between team members and their sense of team-belonging [36]. TMT heterogeneity can integrate various information for the team and may also lead to conflicts that impede TMT's ability to reach consensus. TMT cognitive conflict improves the quality of information exchange, but the emotion conflict triggered by cognitive conflict can hurt the team's cohesion and the quality of their decision-making [37]. Therefore, emotion conflict should be eliminated by emotional fusion. Emotional fusion in TMTs refers to interactive processes that enhance emotional trust, dissolve conflicts, and improve cohesive force among members. Team cohesion and team performance are closely related [38]. In a team with high cohesion, members' fidelity to the team can be improved, a good working atmosphere can be formed, and mutual influence among members can be strengthened. In this way, members can steadily respond to the team's demands, which can, in turn, improve team performance. Therefore, the emotional fusion of TMTs in mixed enterprises is an important factor that affects team decision quality. Improving team fusion results from continuously developing the team. From the beginning, team members are familiar with each other and jockey for position. After experiencing conflicts or disagreement, they gradually reach consensus and establish norms, focusing on efficiency and coordination and finally achieving integration [36]. Hence, by encouraging TMT members to express their own opinions and innovations, stimulating them to make strategic decisions together, and granting them decisionmaking power, they will be more willing to fully exercise their own power. It is an effective solution to reduce emotional conflict and create emotional fusion of TMT.

Organizations often experience friction and incompatibility [28]. This is because SOEs and non-SOEs have different corporate cultures and management styles, and, after integration, TMTs must deal with conflicting corporate management philosophies and values [39]. Thus, in the absence of emotional fusion, personal incompatibilities may arise, which can make the team atmosphere tense and hinder the dissemination of useful information for decision-making. The heterogeneous ownership of mixed enterprises creates a potential emotional fracture zone that can create conflicts of interest and affect decision-making quality [40]. Team cohesion can reduce such friction. Thus, emotional fusion among TMT members in mixed enterprises can help resolve conflicts and enhance team cohesion. Therefore, we propose the following hypothesis.

Hypothesis 3. Emotional fusion mediates the process of TMT cognitive heterogeneity, influencing strategic decision quality.

\subsection{Moderating Effect of Entrepreneurial Spirit.} Entrepreneurial spirit is the driving force of economic growth, and efficiency improvements brought about by innovation represent the optimal practice of entrepreneurship [41]. According to Drucker [15], the essence of the entrepreneurial spirit consists of targeted, systematic organizational innovation that substantially improves productivity and creates value by changing products and services. Zhang [42] suggested that SOE managers are not truly entrepreneurial due to the peculiarity of the principal-agent relationship and the finiteness of the liabilities they assume. However, in the mixed-enterprise context, SOE managers must innovate to improve allocation efficiency, participate in intense market competition, and undertake market risks. In this sense, they too are entrepreneurs characterized by innovative thinking [43]. The cultivation of an entrepreneurial spirit among the TMTs of mixed-reform SOEs does not, therefore, contravene with the form of enterprise ownership. Only when an enterprise is managed by a TMT with a true entrepreneurial spirit can various problems facing the organization be effectively solved. Fritsch and Mueller [44] proposed three dimensions of entrepreneurship -innovation, risk taking, and proactive action-taking them as criteria for judging whether an individual or organization possesses an entrepreneurial spirit. Several studies have adopted these criteria. Chen [45], for example, added collective innovation, cognitive sharing, risk sharing, and collaborative progress to the criteria for assessing the entrepreneurial spirit of TMTs.

TMT members imbued with collective innovation will actively identify innovative opportunities, collect information, exchange opinions to deal with decision-making problems, and gladly adopt democratic decision-making practices. In making decisions, heterogeneous members can scientifically evaluate the potential risks and rewards of different decisions from different perspectives. Sharing cognition can broaden the individual's cognitive boundaries, improve the overall cognitive level of the team, reduce pickup behavior, and provide sufficient information resources for high-quality decision-making.

Mixed-ownership reform faces various uncertainties, and risks can arise when members consider decision-making from their individual knowledge base, and heterogeneous members might also have different risk preferences. However, a sense of risk sharing can promote integration between risk-averse and risk-tolerant team members, helping to reach consensus so they will not miss opportunities for innovation. In addition, if TMT members are only willing to work independently and lack coordination with other, even with an innovative sense, the team ultimately lacks an entrepreneurial spirit. A cooperative and progressive entrepreneurial spirit can enable the heterogeneous knowledge and capacities of team members to work together, which will improve the efficiency and quality of information processing. Therefore, we propose the following hypothesis.

Hypothesis 4. Entrepreneurial spirit positively moderates the effect of information integration on strategic decision quality and moderates the mediating effect of information integration.

Since TMT cognitive heterogeneity can create conflict, collective innovation can consolidate team members' strength to produce a centripetal force for the organization, 
thereby promoting decision-making. If team members lack a spirit of collective innovation, individuals or subgroups may jockey for position, destroying the harmonious atmosphere and hindering integration. Cognitive sharing can help eliminate information asymmetry, facilitate the heterogeneous cognition of decision-making problems, and enhance close connections. In a complicated and changing context of reform, decisions must be made based on a great deal of fuzzy information. Risk sharing can alleviate the pressure on team members to undertake risks independently, thus avoiding a failure to innovate over fears of potential risks. While heterogeneous TMT members will inevitably disagree, the desire for collaborative progress can facilitate consensus, avoid decision-making failure, and increase interdependence among members in the joint pursuit of goals. Therefore, we propose the following hypothesis.

Hypothesis 5. Entrepreneurial spirit positively moderates the effect of emotional fusion on strategic decision quality and moderates the mediation effect of emotional fusion.

Figure 1 shows the theoretical framework of the study.

\section{Method}

4.1. Research Objects and the Survey. Three commercial companies in Shanghai, one of the most developed regions of mixed-ownership enterprises in China, were selected for in-depth interviews, and a questionnaire was designed based on the literature and interview results. A total of 160 mixedownership enterprises (state-owned, private, and foreign cross-owned enterprises) in eight provinces and cities (Shanghai, Jiangsu, Zhejiang, Guangdong, Beijing, Heilongjiang, Inner Mongolia, and Xinjiang) were selected for the survey. The survey was conducted in two ways: (1) MBA students delivered questionnaires to TMTs and collected and returned the completed surveys, and (2) questionnaires were sent via e-mail or post, relying on management consultancies to contact the relevant people. The objects of the questionnaire were TMT members involved in decisionmaking within an enterprise. Each TMT member of the 160 enterprises had one questionnaire. In total, 1,249 questionnaires were distributed, and 906 were collected. Questionnaires from those with incomplete data were eliminated. Finally, 727 valid questionnaires from 107 enterprises were collected (effective recovery rate of questionnaires: 68.8\%). Respondents below 30 years of age accounted for $0.4 \%$; $29.7 \%$ were $31-40$ years old; $53.8 \%$ were $41-50$ years old; and $16.1 \%$ were 51 years old or older. Meanwhile, $8.8 \%$ had some college or no college; $44.7 \%$ had an undergraduate education; and $46.5 \%$ had a master's degree or above. Finally, $74.6 \%$ had been in their position for less than five years, while $25.4 \%$ had held their position for more than five years.

4.2. Measurement Tools. All items used the seven-point Likert scale $(1=$ "completely disagree" and $7=$ "completely agree"). Their details are given in the Appendix.

Based on Zhao et al.'s work [46], cognitive heterogeneity was measured in three dimensions: enterprise development

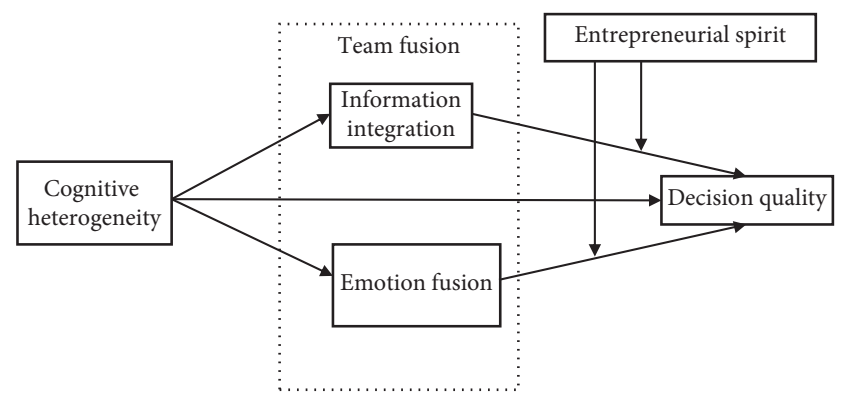

Figure 1: Theoretical framework of the study.

route, competitive advantage, and scheme implementation, such as the item "Long-term enterprise development routes are not unified within the team." Cronbach's $\alpha$ coefficient was 0.847 .

Team fusion was mainly measured in the two dimensions of information integration and emotional fusion. The measurement of information integration referred to the questionnaire proposed by Simsek et al. [47]. There were three items, such as "Team members often communicate their different opinions on decision-making problems." In our study, Cronbach's $\alpha$ coefficient was 0.804 . The measurement of emotional fusion referred to Ge's [32] questionnaire for measuring emotional trust and conflict management. There were three items, such as "Team members can share freely their ideas, feelings, and expectations to create a good sharing atmosphere." Cronbach's $\alpha$ coefficient was 0.817 .

The measurement of entrepreneurial spirit referred to Chen and Hao's work [16] and included the four dimensions of collective innovation, cognition sharing, risk sharing, and collaborative progress. There were eight items, such as "Each member is willing to acquire resources in multiple ways to form innovative decision-making schemes." Cronbach's $\alpha$ coefficient was 0.829 .

The measurement of strategic decision quality referred to the questionnaire designed by Huang et al. [48] to define the high-quality development of SOEs and included the two dimensions of resource allocation efficiency and innovativeness. It had three items, such as “The team's decisionmaking scheme has positive effects for the enterprise to improve resource allocation efficiency." Cronbach's $\alpha$ coefficient was 0.792 .

The control variables included the members of the TMT as well as age, education, and tenure. The values for education were as follows: $1=$ some college or less; $2=$ undergraduate degree; and $3=$ master's degree or above.

Amos 24.0 and SPSS 25.0 were used for statistical analysis.

\section{Results}

5.1. Confirmatory Factor Analysis and Validity Test. Confirmatory factor analysis in AMOS tested the validity of the five variables (i.e., cognitive heterogeneity, information integration, team fusion, entrepreneurial spirit, and strategic decision quality). Table 1 indicates that all fit indexes of the 
TABLE 1: Confirmatory factor analysis.

\begin{tabular}{llccrr}
\hline Fit indexes & & $\chi^{2} / \mathrm{d} f$ & RMSEA & TLI & CFI \\
\hline Five-factor model & CH; II; EF; ES; DQ & 1.543 & 0.037 & 0.979 & 0.984 \\
Four-factor model & CH; II + EF; ES; DQ & 5.612 & 0.091 & 0.853 & 0.876 \\
Three-factor model & CH; II + EF + ES; DQ & 8.608 & 0.137 & 0.705 & 0.766 \\
Two-factor model & CH + II + EF + ES; DQ & 13.691 & 0.177 & 0.508 & 0.576 \\
One-factor model & CH + II + EF + ES + DQ & 17.691 & 0.203 & 0.353 & 0.767 \\
\hline
\end{tabular}

Notes: $\mathrm{CH}$ is cognitive heterogeneity; II is information integration; EF is emotional fusion; ES is entrepreneurial spirit; DQ is strategic decision quality.

five-factor model are ideal $\left(\chi^{2} / \mathrm{d} f=1.543\right.$, RMSEA $=0.037$, $\mathrm{IFI}=0.984, \mathrm{CFI}=0.984$, and TLI $=0.979)$. The fit coefficients are better than those of the other models in the table, indicating that the variables have better discriminate validity.

5.1.1. Aggregation Test. To check whether the measurement results of the individual variables could aggregate to the team level, we adopted the intrateam consistency coefficient Rwg and the interteam diversity factors ICC(1) and ICC(2). Table 2 shows that all the five variables satisfied the aggregation standards of Rwg > 0.7, ICC(1) > 0.05, and ICC(2) $>0.5$, indicating that the individual data of the five variables could aggregate to the team level for statistical analysis.

Since self-report questionnaires and single-source data can lead to common-method variance, Harman's singlefactor test was adopted. Twenty terms were placed at the same time in one exploratory factor analysis. The variance explanation rate of the first common factor extracted from the analysis results of unrotated factors was $32.252 \%$, which is below $40 \%$, indicating that the influence of commonsource deviation on the data was within the acceptable scope.

5.1.2. Descriptive Statistical Analysis and Correlation Analysis. Table 3 shows that strategic decision quality $(r=0.282, p<0.01)$, information integration $(r=0.277$, $p<0.01)$, and emotional fusion $(r=0.163, p<0.01)$ were significantly positively correlated with cognitive heterogeneity. Information integration $(r=0.326, p<0.01)$ and emotional fusion $(r=0.352, p<0.01)$ were significantly positively correlated with strategic decision quality.

5.1.3. Test Results for the Hypotheses. Hierarchical regression was used to test the hypotheses; Table 4 shows the results. As can be seen from Model 1 and Model 2, the independent variable cognitive heterogeneity had a significant positive correlation with the mediating variable information integration $(\beta=0.78, p<0.01)$ and emotional fusion $(\beta=0.275$, $p<0.001)$. Model 3 shows that the independent variable cognitive heterogeneity has a significant positive correlation with the dependent variable strategic decision quality ( $\beta=0.265, p<0.001)$; thus, Hypothesis 1 is supported. From Model 4 , we see that the mediating variables information integration $(\beta=0.223, p<0.001)$ and emotional fusion $(\beta=0.240, p<0.001)$ have significant positive correlations with the dependent variable, strategic decision quality. After adding the mediating variable, the positive influence of cognitive heterogeneity on strategic decision quality is still significant $(\beta=0.161, p<0.001)$ but weaker. It can thus be seen that information integration and emotional fusion have partial mediating effects between cognitive heterogeneity and strategic decision quality. From Model 5, we see that the interactive term between entrepreneurial spirit and information $(\beta=0.189, p<0.05)$, emotional fusion $(\beta=0.151$, $p<0.05)$, and strategic decision quality is positively correlated.

To further verify the mediating effects of information integration and emotional fusion and the regulating function of entrepreneurial spirit, we adopted the deviationcorrected percentile bootstrap method, as recommended by Fang et al. [49]. PROCESS 3.1 in SPSS was used to analyze the mediation model, the regulation model, and the combined model. A total of 5,000 bootstrapped samples were used, and the confidence interval result was 95\%. Table 5 displays the results of bootstrapping analysis for the mediating effects. The indirect effects of cognitive heterogeneity on strategic decision quality through information integration and emotional fusion were 0.061 and 0.043 , respectively; the total indirect effect was 0.104; and the direct effect was 0.161 . Since 0 is not included in the confidence interval, the mediation relations were all significant, and some showed mediating effects. Thus, Hypotheses 2 and 3 are supported: information integration and emotional fusion have mediating effects between cognitive heterogeneity and strategic decision quality.

To verify the adjusted mediating effect, the indirect effect of the variable under different values was directly obtained through the process operation. This automatically operates different values by reducing one standard deviation and adding one standard deviation based on the mean value of the moderating variable (entrepreneurial spirit) to form the low and high groups. Table 6 shows that when entrepreneurial spirit is weak, the indirect effect of cognitive heterogeneity on strategic decision quality through information integration is 0.018 . Zero is included in the confidence interval, indicating that when entrepreneurial spirit is weak, the indirect effect of cognitive heterogeneity on strategic decision quality through information integration is not significant. When entrepreneurial spirit is strong, the indirect effect of cognitive heterogeneity on strategic decision quality through information integration is 0.081 . Zero is not included in the confidence interval, indicating that when entrepreneurial spirit is strong, the indirect effect of cognitive heterogeneity on strategic decision quality through information integration is significant. In addition, as seen in the adjusted coefficient of the mediating effect, the effect value is 0.052 (confidence interval $[0.013,0.096]$ ). Zero is not 
Table 2: Aggregation test.

\begin{tabular}{lccc}
\hline Variables & Rwg & ICC (1) & ICC (2) \\
\hline Cognitive heterogeneity & 0.801 & 0.491 & 0.870 \\
Information integration & 0.798 & 0.387 & 0.815 \\
Emotional fusion & 0.832 & 0.479 & 0.865 \\
Entrepreneurial spirit & 0.796 & 0.432 & 0.753 \\
Strategic decision quality & 0.757 & 0.488 & 0.869 \\
\hline
\end{tabular}

Common-method variance test.

TABLE 3: Standard deviations, mean values, and correlation coefficients of the variables.

\begin{tabular}{|c|c|c|c|c|c|c|c|c|c|c|}
\hline & Mean value & Standard deviation & 1 & 2 & 3 & 4 & 5 & 6 & 7 & 8 \\
\hline (1) Team members & 6.793 & 1.841 & & & & & & & & \\
\hline (2) Age & 43.580 & 5.627 & -0.027 & & & & & & & \\
\hline (3) Education & 2.377 & 0.643 & 0.005 & 0.051 & & & & & & \\
\hline (4) Tenure & 3.200 & 1.186 & $0.155^{* *}$ & -0.046 & 0.065 & & & & & \\
\hline (5) Cognitive heterogeneity & 4.994 & 1.096 & 0.102 & -0.055 & 0.064 & 0.049 & & & & \\
\hline (6) Information integration & 4.732 & 1.089 & 0.025 & 0.060 & 0.081 & 0.033 & $0.277^{* *}$ & & & \\
\hline (7) Emotional fusion & 4.452 & 1.246 & -0.011 & -0.003 & 0.091 & $0.136^{*}$ & $0.163^{* *}$ & $0.222^{* *}$ & & \\
\hline (8) Entrepreneurial spirit & 4.679 & 1.132 & 0.280 & 0.419 & 0.383 & 0.265 & $0.121^{*}$ & $0.257^{* *}$ & $0.358^{* *}$ & \\
\hline (9) Strategic decision quality & 4.527 & 1.136 & $0.237^{* *}$ & -0.013 & $0.151^{* *}$ & $0.164^{* *}$ & $0.282^{* *}$ & $0.326^{* *}$ & $0.352^{* *}$ & $0.348^{* *}$ \\
\hline
\end{tabular}

Note: ${ }^{*} p<0.05 ;{ }^{* *} p<0.01 ;{ }^{* * *} p<0.001$.

TABLE 4: Results of hierarchical regression analysis.

\begin{tabular}{|c|c|c|c|c|c|}
\hline \multirow{2}{*}{ Dependent variables } & \multirow{2}{*}{$\begin{array}{c}\text { Information integration } \\
\text { Model } 1 \\
\end{array}$} & \multirow{2}{*}{$\begin{array}{c}\text { Emotional fusion } \\
\text { Model } 2\end{array}$} & \multicolumn{3}{|c|}{ Strategic decision quality } \\
\hline & & & Model 3 & Model 4 & Model 5 \\
\hline Team scale & -0.028 & 0.002 & 0.102 & 0.109 & $0.112^{* * *}$ \\
\hline Age & 0.001 & 0.012 & 0.002 & -0.001 & -0.002 \\
\hline Education & 0.135 & 0.094 & 0.206 & 0.153 & $0.161^{*}$ \\
\hline Term & $0.130^{*}$ & -0.008 & 0.106 & 0.076 & 0.071 \\
\hline Cognitive heterogeneity & $0.178^{* *}$ & $0.275^{* * *}$ & $0.265^{* * *}$ & $0.161^{* * *}$ & $0.175^{* * *}$ \\
\hline Information integration & & & & $0.223^{* * *}$ & $0.180^{* * *}$ \\
\hline Emotional fusion & & & & $0.240^{* * *}$ & $0.180^{* * *}$ \\
\hline Entrepreneurial spirit & & & & & $0.308^{* * *}$ \\
\hline Information integration $\times$ entrepreneurial spirit & & & & & $0.189^{*}$ \\
\hline Emotional fusion $\times$ entrepreneurial spirit & & & & & $0.151^{*}$ \\
\hline$R^{2}$ & 0.048 & 0.084 & 0.140 & 0.267 & 0.334 \\
\hline$F$ & $4.013^{*}$ & $7.366^{* * *}$ & $12.970^{* * *}$ & $20.695^{* * *}$ & $19.813^{* * *}$ \\
\hline
\end{tabular}

Note: $N=727 ;{ }^{*} p<0.05 ;{ }^{* *} p<0.01 ;{ }^{* * *} p<0.001$.

TABLE 5: Bootstrapping analysis results of the mediating effects.

\begin{tabular}{|c|c|c|c|c|}
\hline Effect & Effect & BootSE & BootLLCI & BootULCI \\
\hline Total effect: cognitive heterogeneity $\longrightarrow$ strategic decision quality & 0.265 & 0.048 & 0.170 & 0.360 \\
\hline Direct effect: cognitive heterogeneity $\longrightarrow$ strategic decision quality & 0.161 & 0.047 & 0.069 & 0.253 \\
\hline Total indirect effect & 0.104 & 0.021 & 0.066 & 0.148 \\
\hline Indirect effect of information integration & 0.061 & 0.015 & 0.033 & 0.093 \\
\hline Indirect effect of emotional fusion & 0.043 & 0.015 & 0.015 & 0.075 \\
\hline Difference comparison of indirect effects & -0.019 & 0.023 & -0.062 & 0.025 \\
\hline
\end{tabular}

included in the confidence interval, indicating that entrepreneurial spirit has an adjusted mediating effect in the path of cognitive heterogeneity influencing strategic decision quality through information integration; thus, Hypothesis 4 is supported.

When entrepreneurial spirit is weak, the indirect effect of cognitive heterogeneity on strategic decision quality through emotional fusion is 0.016 . Zero is included in the confidence interval, indicating that when entrepreneurial spirit is weak, the indirect effect of cognitive heterogeneity on strategic decision quality through emotional fusion is not significant. When entrepreneurial spirit is strong, the indirect effect of cognitive heterogeneity on strategic decision quality through emotional fusion is 0.048. Zero is not included in the confidence interval, indicating that when entrepreneurial spirit is strong, the indirect effect of cognitive heterogeneity 
TABle 6: Analysis of moderate mediating effect.

\begin{tabular}{|c|c|c|c|c|c|}
\hline Indirect effect & $\begin{array}{l}\text { Entrepreneurial } \\
\text { spirit }\end{array}$ & Effect & BootSE & BootLLCI & BootULCI \\
\hline \multirow{4}{*}{$\begin{array}{l}\text { Cognitive heterogeneity } \longrightarrow \text { information integration } \longrightarrow \text { strategic decision } \\
\text { quality }\end{array}$} & $-1 \mathrm{SD}$ & 0.018 & 0.016 & -0.014 & 0.051 \\
\hline & SD & 0.049 & 0.014 & 0.024 & 0.079 \\
\hline & $1 S D$ & 0.081 & 0.021 & 0.042 & 0.124 \\
\hline & $\begin{array}{l}\text { Moderated } \\
\text { mediation }\end{array}$ & 0.052 & 0.021 & 0.013 & 0.096 \\
\hline \multirow{4}{*}{$\begin{array}{l}\text { Cognitive heterogeneity } \longrightarrow \text { emotional fusion } \longrightarrow \text { strategic decision } \\
\text { quality }\end{array}$} & $-1 S D$ & 0.016 & 0.012 & -0.005 & 0.043 \\
\hline & SD & 0.032 & 0.012 & 0.010 & 0.058 \\
\hline & $1 \mathrm{SD}$ & 0.048 & 0.018 & 0.017 & 0.087 \\
\hline & $\begin{array}{l}\text { Moderated } \\
\text { mediation }\end{array}$ & 0.027 & 0.015 & 0.002 & 0.062 \\
\hline
\end{tabular}

on strategic decision quality through emotional fusion is significant. In addition, as seen in the adjusted mediating coefficient, the effect value is 0.027 . Zero is not included in the confidence interval, indicating that entrepreneurial spirit has an adjusted mediating effect in the path of cognitive heterogeneity influencing strategic decision quality through emotional fusion; thus, Hypothesis 5 is confirmed.

To more intuitively demonstrate the mediating effects of entrepreneurial spirit, we plot them in Figures 2 and 3, where the slopes with strong entrepreneurial spirit are steeper than those with weak entrepreneurial spirit. This suggests that the stronger the entrepreneurial spirit, the larger the increase in strategic decision quality caused by TMT information integration and emotional fusion.

\section{Conclusion}

Based on the data from 107 Chinese enterprises, this paper tested the effects of TMT cognitive heterogeneity on strategic decision quality in mixed enterprises, along with the team fusion's mediating function under the moderation of entrepreneurship. The following conclusions are obtained:

(i) TMT cognitive heterogeneity had a significant positive effect on strategic decision quality. That is, given mixed-ownership reform, cognitive heterogeneity can enhance TMTs' strategic decision quality on sustainability.

(ii) Team fusion with information integration and emotional fusion had a mediating effect between TMT cognitive heterogeneity and strategic decision quality.

(iii) Entrepreneurial spirit positively impacted the relationship between information integration, emotional fusion, and strategic decision quality. The stronger the entrepreneurial spirit, the greater the influence of information integration and emotional fusion on strategic decision quality.

\section{Discussion}

7.1. Theoretical Significance. This paper discusses the practical problem of how to integrate a decision-making team to improve the quality of their strategic decision-making for

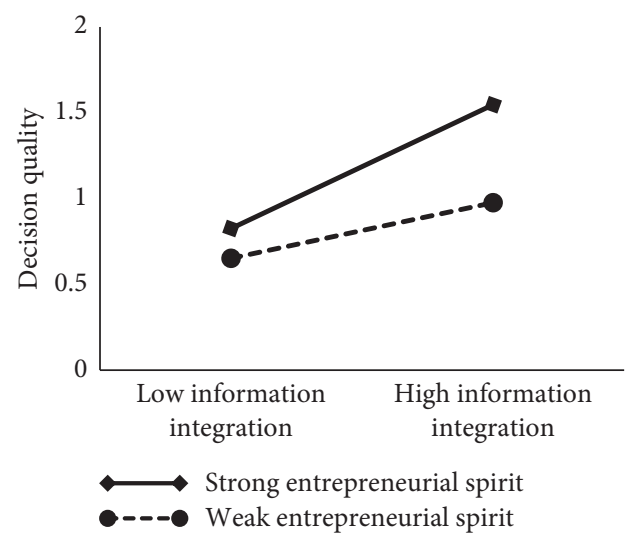

FIGURE 2: Moderating effect of information integration.

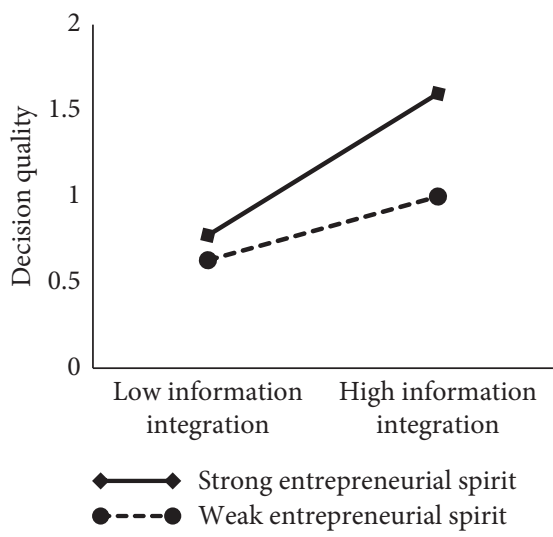

Figure 3: Moderating effect of emotional fusion.

sustainability. It addresses the research gap in the literature focusing only on share design and other institutional arrangements. Moreover, it provides a theoretical basis for solving the problem of "mixed but not fusion." Based on upper echelon theory, this paper explored the effect of TMT cognitive heterogeneity on strategic decision quality. This work also examined the mediating effect of TMT entrepreneurial spirit; its theoretical significance is as follows.

First, based on Huang et al.'s work [48], the measurement dimensions of strategic decision quality were designed, including resource allocation efficiency and decision-making innovativeness. The empirical results are inconsistent 
with Olson et al. [11] who found that cognitive heterogeneity was negatively correlated with team's decision-making performance. In our study, TMT cognitive heterogeneity not only positively correlated with strategic decision quality but also supported innovative decision-making. Given China's mixed-ownership reform, the stronger the TMT cognitive heterogeneity is, the more helpful it is for processing diversified, fuzzy information and identifying new opportunities from it, thereby supporting strategic decision-making in a complicated, changing environment.

Second, based on the concept of team fusion under the logic of "characteristic-process-result," the behavioral and psychological dimensions of TMT fusion were defined, and their mediating effects between TMT cognitive heterogeneity and strategic decision quality were examined. In addition, the mediating mechanism of TMT cognitive heterogeneity in strategic decision quality through information integration and emotional fusion was revealed. This expands our understanding of the black box of integration given China's mixed-ownership reform.

Third, this paper expanded research on entrepreneurial spirit from the individual level to the team level, enriching research on TMT entrepreneurship. Despite the considerable interest in entrepreneurial spirit, theoretical studies of TMT entrepreneurial spirit are lacking, especially whether the managers of SOEs can be considered entrepreneurs. Our study supports Wang and $\mathrm{Xu}$ [28] in that SOE managers are entrepreneurs with entrepreneurial spirit. Moreover, following Chen and Hao [16], our study found that the entrepreneurial spirit of collective innovation, cognition sharing, risk sharing, and collaborative progress can strengthen the positive effects of TMT fusion on strategic decision quality.

7.2. Implications for Sustainability. Our study has the following implications for sustainable development. First, the mixed-ownership reform of Chinese enterprises is an important measure to integrate resources and realize the sustainable development. TMT's heterogeneous cognition of sustainable development should consider the dual objectives of economic interests and environmental responsibility. Under the mixed-ownership reform, SOE TMTs should reallocate and integrate resources related to sustainability. Decision-making to achieve low-carbon development is a complex process. In the face of the need for environmentfriendly operations, TMT cognitive heterogeneity can help TMTs collect more comprehensive information from diversified viewpoints and deepen their understanding of decision problems, which can support innovative, highquality decision-making. Second, TMTs organize and coordinate the sustainable development of enterprises, and whether mixed-ownership reform succeeds depends on whether TMT members can effectively integrate to achieve win-win cooperation. Information integration and emotional fusion are effective ways to achieve team fusion. On the one hand, strengthening information exchange and cognition sharing within the team can integrate diverse viewpoints into comprehensive thinking about decision- making problems, which can avoid decision failures caused by a lack of environmental perspectives. On the other hand, TMT cognitive heterogeneity will inevitably cause disagreements about low-carbon development, making it necessary to resolve conflicts through active communication and interaction, forge a harmonious working atmosphere, promote emotional fusion, enhance team cohesion, and stimulate members to make high-level contributions to the team. Third, it is important to cultivate TMTs' entrepreneurial spirit, especially among team members who represent state-owned capital. The entrepreneurial spirit of SOE managers is relatively weak, mainly because of the fear of risk and insufficient motivation. In addition, it is necessary to improve the environmental awareness of the managers of non-SOEs and promote the idea of gaining competitive advantages through green innovation and low-carbon strategy. With the mixed-ownership reform, emphasis should be placed on stimulating the TMT entrepreneurial spirit based on collective innovation, cognition sharing, risk sharing, and collaborative progress. In this way, mixedownership enterprises can develop under high-quality lowcarbon strategies in sustainable practices.

7.3. Limitations and Future Research. This paper has some limitations. First, because of the difficulty of collecting TMT data in the psychological dimension, a vertical research design was not adopted. Cross-sectional data have some defects, and it is possible that the deduced causality had the opposite causal relationship. Future research should conduct longitudinal analysis to improve the results. Second, although the scales used in this paper were based on the literature, as well as discussions with experts and TMT members, there are still some measurement limitations. For example, the specificity of TMT cognition in mixed-ownership enterprises was not mentioned. As such, future research should develop high-quality scales. In addition, the sample size in this paper was not large, thus limiting universality and representativeness. Also, this research can be extended and enriched by directly addressing corporate social responsibility [50] or focusing on more specific decision scenarios such as dual-channel supply chains [51].

\section{Appendix}

Cognitive Heterogeneity

(1) Long-term enterprise development routes are not unified within the team

(2) There are different opinions on how to maintain the maximum competitive advantages of the enterprise within the team

(3) There are frequent disputes over the implementation scheme of enterprise strategies within the team

Information Integration

(1) Team members often communicate their different opinions on decision-making problems

(2) Team members often raise creative innovation schemes and actively discuss them 
(3) Team members often communicate how the information they have collected affects the other members' work

Emotional Fusion

(1) Team members can freely share their ideas, feelings, and expectations to create a good sharing atmosphere

(2) Team members can share the difficulties they face in work and life with other members, who can express their concerns and make constructive suggestions

(3) When faced with conflicts among team members, they can seek the solution most favorable to the group

Entrepreneurial Spirit

(1) Each member is willing to acquire resources by multiple means to form innovative decision-making schemes

(2) The team likes to perfect solutions based on collective wisdom

(3) Members possess new knowledge that is required for decision-making and are willing to share it with other team members

(4) Members have new ideas about problems under discussion and are willing to share them with the team

(5) The team members are willing to deeply discuss the costs and revenues of new projects

(6) The team members will not find fault with each other if the expected revenue of the project is not achieved

(7) Members are sensitive to dynamic changes in the external environment and are good at identifying changes and opportunities

(8) Members unanimously agree to pursue excellent standards

Strategic Decision Quality

(1) The team's decision-making scheme has positive effects for the enterprise for improving resource allocation efficiency

(2) The team's decision-making scheme is innovative and can improve the enterprise's way of creating value

(3) The team's decision-making represents a forwardlooking strategy based on changes in the external macroenvironment and the latest developments in the industry or field

\section{Data Availability}

Data are available upon request.

\section{Conflicts of Interest}

The authors declare that there are no conflicts of interest regarding the publication of this paper.

\section{Acknowledgments}

This research was funded by the thesis funding support (University of Shanghai for Science and Technology): Research Planning Fund for Humanities and Social Sciences of the Ministry of Education: research on the influence of TMT cognitive evolution on decision performance based on team life cycle (Grant no. 17YJA630020), the Shanghai First-Class Academic Discipline Project (Grant no. S1201YLXK), and the Hujiang Foundation of China (Grant no. A14006). Dr. Hu's research is supported by China National Social Science Foundation (Grant no. 13CTQ042) and the First-Class Undergraduate Construction Project of Shanghai HighLevel Local Applied Universities (Shanghai Lixin University of Accounting and Finance).

\section{References}

[1] Y. Sheng, "The intension and specific tasks of the new round of mixed ownership reform of state-owned enterprises," Reform, vol. 312, no. 2, pp. 125-137, 2020.

[2] S. Sharma and I. Henriques, "Stakeholder influences on sustainability practices in the Canadian forest products industry," Strategic Management Journal, vol. 26, no. 2, pp. 159-180, 2005.

[3] W. Li and M. Yu, "Ownership structure and innovation of privatizational enterprises," Management World, vol. 2015, no. 4, pp. 112-125, 2015.

[4] H. Liu, Y. Qi, and X. Xie, "The allocation logic of equity ownership and control rights from equivalence to nonequivalence: an empirical test of listed companies with mixed-ownership under the supervision of SASAC," Economic Research Journal, vol. 53, no. 5, pp. 175-189, 2018.

[5] Z. Xie and L. Chen, "The impacts of ownership, competition and corporate governance on the performance of Chinese SOE's reform: a meta-regression analysis," Luojia Management Review, vol. 6, no. 2, pp. 95-106, 2012.

[6] D. Pujari, G. Wright, and K. Peattie, "Green and competitive: influences on environmental new product development performance," Journal of Business Research, vol. 56, no. 8, pp. $657-671,2003$

[7] H. Cao and Z. Chen, "The driving effect of internal and external environment on green innovation strategy: the moderating role of top management's environmental awareness," Nankai Business Review, vol. 20, no. 6, pp. 95-103, 2017.

[8] D. C. Hambrick and P. A. Mason, "Upper echelons: the organization as a reflection of its top managers," The Academy of Management Review, vol. 9, no. 2, pp. 193-206, 1984.

[9] J. Yang, N. Hou, and X. Deng, "Influence of member heterogeneity on team innovation performance based on learning space: moderating role of team identity on learning space," Chinese Journal of Management, vol. 11, no. 7, pp. 1021-1028, 2014.

[10] M. J. Hornsey, "Social identity theory and self-categorization theory: a historical review," Social and Personality Psychology Compass, vol. 2, no. 1, pp. 204-222, 2008.

[11] B. J. Olson, Y. Bao, and S. Parayitam, "Strategic decision making within Chinese firms: the effects of cognitive diversity and trust on decision outcomes," Journal of World Business, vol. 42, no. 1, pp. 35-46, 2007. 
[12] C. C. Miller, L. M. Burke, and W. H. Glick, "Cognitive diversity among upper-echelon executives: implications for strategic decision processes," Strategic Management Journal, vol. 19, no. 1, pp. 39-58, 1998.

[13] S. Chen and C. Lu, "State-owned enterprise managers' cross system ties and reform of composite-ownership system," Management World, vol. 2017, no. 5, pp. 107-118, 2017.

[14] Z. Song, "Mechanism revolution and entrepreneurship," State-Owned Assets Report, vol. 2018, no. 1, pp. 11-13, 2018.

[15] P. F. Drucker, Innovation and Entrepreneurship: Practice and Principles, China Machine Press, Beijing, China, 2018.

[16] Z. W. Chen and X. L. Hao, "Empirical study of relationship between entrepreneurship of entrepreneurial team and corporate performance," Journal of Management Sciences, vol. 21, no. 1, pp. 39-48, 2008.

[17] J. Xu, K. Yun, F. Yan, P. Jang, J. Kim, and C. Pang, "A study on the effect of TMT characteristics and vertical dyad similarity on enterprise achievements," Sustainability, vol. 11, no. 10, p. $2913,2019$.

[18] R. S. Dooley and G. E. Fryxell, "Attaining decision quality and commitment from dissent: the moderating effects of loyalty and competence in strategic decision-making teams," Academy of Management Journal, vol. 42, no. 4, pp. 389-402, 1999.

[19] S. S. Levine, M. Bernard, and R. Nagel, "Strategic intelligence: the cognitive capability to anticipate competitor behaviour," Strategic Management Journal, vol. 39, no. 2, p. 527, 2018.

[20] D. C. Hambrick, S. E. Humphrey, and A. Gupta, "Structural interdependence within top management teams: a key moderator of upper echelons predictions," Strategic Management Journal, vol. 36, no. 3, pp. 449-461, 2015.

[21] Y. Fu, "Research on the impact mechanism of TMT cognition on organizational ambidexterity: from organizational character perspective," Advances in Psychological Science, vol. 26, no. 1, pp. 14-25, 2018.

[22] D. C. Hambrick, T. S. Cho, and M.-J. Chen, "The influence of top management team heterogeneity on firms' competitive moves," Administrative Science Quarterly, vol. 41, no. 4, pp. 659-684, 1996.

[23] T. Kochan, K. Bezrukova, R. Ely et al., "The effects of diversity on business performance: report of the diversity research network," Human Resource Management, vol. 42, no. 1, pp. 3-21, 2003.

[24] C. Boone, B. Lokshin, H. Guenter, and R. Belderbos, “Top management team nationality diversity, corporate entrepreneurship, and innovation in multinational firms," Strategic Management Journal, vol. 40, no. 2, pp. 277-302, 2019.

[25] I. Aggarwal and A. W. Woolley, "Team creativity, cognition, and cognitive style diversity," Management Science, vol. 65, no. 4, pp. 1586-1599, 2019.

[26] A. Sahaym, S. Y. Cho, S. K. Kim, and F.-T. Mousa, "Mixed blessings: how top management team heterogeneity and governance structure influence the use of corporate venture capital by post-IPO firms," Journal of Business Research, vol. 69, no. 3, pp. 1208-1218, 2016.

[27] S. Rodan and C. Galunic, "More than network structure: how knowledge heterogeneity influences managerial performance and innovativeness," Strategic Management Journal, vol. 2004, no. 25, pp. 541-562, 2004.

[28] S. Wang and Y. Xu, "Empirical study on the development of private enterprises and the reform of mixed ownership: path choice and policy framework," Journal of Chinese Academy of Governance, vol. 2017, no. 5, pp. 78-84, 2017.

[29] M. A. Campion, E. M. Papper, and G. J. Medsker, "Relations between work team characteristics and effectiveness: a replication and extension," Personnel Psychology, vol. 49, no. 2, pp. 429-452, 1996.

[30] H. Wu and X. Yao, "A revisit to top management team in an interaction-based social capital view," Chinese Journal of Management, vol. 9, no. 9, pp. 1300-1306, 2012.

[31] M. Bruccoleri, F. Riccobono, and A. Größler, "Shared leadership regulates operational team performance in the presence of extreme decisional consensus/conflict: evidences from business process reengineering," Decision Sciences, vol. 50, no. 1, pp. 46-83, 2019.

[32] Y. H. Ge, Research on the Influence of the Characteristics of Upper Echelon on the Behavior and Performance of Enterprises, Science Press, Beijing, China, 2017.

[33] D. C. Hambrick, "Upper echelons theory: an update," Academy of Management Review, vol. 32, no. 2, pp. 334-343, 2007.

[34] J. Lv and G. Zhang, "The mechanisms of knowledge heterogeneity on creativity of knowledge teams: an interactive cognition perspective," Acta Psychologica Sinica, vol. 47, no. 4, pp. 533-544, 2015.

[35] Y. Zheng, C. Chen, and B. Hua, "A review on strategic decision process studies based on cognitive perspective: an integrated research framework," Nanjing Business Review, vol. 2015, no. 2, pp. 188-205, 2015.

[36] H. Sun and H. Ma, "Opportunity development, entrepreneurship bricolage and team fusion-a case study based on the Timmons model," Science Research Management, vol. 37, no. 7, pp. 97-106, 2016.

[37] Y. Q. Yi, Y. Liu, and M. Gu, "The double-edged sword effect on innovative orientation of top management team cognitive conflict," Chinese Journal of Management, vol. 15, no. 11, pp. 1663-1670, 2018.

[38] M. Chiniara and K. Bentein, "The servant leadership advantage: when perceiving low differentiation in leadermember relationship quality influences team cohesion, team task performance and service OCB," The Leadership Quarterly, vol. 29, no. 2, pp. 333-345, 2018.

[39] S. J. Huang, "On the mixed ownership reform of Chinese state owned enterprises," Economic Management Journal, vol. 36, no. 7, pp. 1-10, 2014.

[40] M. Lin, H. F. Qi, and X. S. Li, "The impact of TMT faultline on the breakthrough innovations of mixed firms: the moderation of structural power equality between state-owned and nonstate-owned TMT members," Forecasting, vol. 35, no. 4, pp. 15-21, 2016.

[41] D. Ahlstrom, A. Y. Chang, and J. S. T. Cheung, "Encouraging entrepreneurship and economic growth," Journal of Risk and Financial Management, vol. 12, no. 4, p. 178, 2019.

[42] W. Zhang, "The biggest problem of state-owned enterprise governance," Directors and Boards, vol. 2014, no. 8, pp. 102-103, 2014.

[43] S. Wang, "Constructing the marketization incentive and innovation mechanism of state-owned enterprises and promoting the sustainable and high-quality development of state-owned enterprises," Xinjiang State Farms Economy, vol. 323, no. 1, pp. 1-6, 2020.

[44] M. Fritsch and P. Mueller, The Evolution of Regional Entrepreneurial Spirit and Growth Regimes, Springer Science, New York, NY, USA, 2006.

[45] Z. Chen, "Dimensions and limits of entrepreneurship in managing a top executive team," Chinese \& Foreign Entrepreneurs, vol. 2006, no. 1, pp. 76-79, 2006.

[46] B. Zhao, Y. Ge, and X. Liu, "TMT cognition, faultline and innovation performance: the moderating effects of strategic 
flexibility," Science of Science and Management of S.\&T, vol. 37, no. 6, pp. 112-122, 2016.

[47] Z. Simsek, J. F. Veiga, M. H. Lubatkin, and R. N. Dino, "Modeling the multilevel determinants of top management team behavioral integration," Academy of Management Journal, vol. 48, no. 1, pp. 69-84, 2005.

[48] S. J. Huang, H. J. Xiao, and X. Wang, "Study on high-quality development of the state-owned enterprises," China Industrial Economics, vol. 2018, no. 10, pp. 19-41, 2018.

[49] J. Fang, M. Q. Zhang, and H. J. Chiou, "Mediation analysis and effect size measurement: retrospect and prospect," Psychological Development and Education, vol. 28, no. 1, pp. 105-111, 2012.

[50] J. Bian, Y. Liao, Y. Wang, and F. Tao, "Analysis of firm CSR strategies," European Journal of Operational Research, In press, 2020

[51] J. Li, Y. Liao, V. Shi, and X. Chen, "Supplier encroachment strategy in the presence of retail strategic inventory: centralization or decentralization?" Omega, In press, 2020. 